\title{
A COMPARATIVE STUDY OF DERMATOGLYPHICS (FINGER TIP PATTERN) IN PATIENTS WITH MYOCARDIAL INFARCTION AND CONTROL GROUP.
}

Amit Kumar Saxena, Prachi Saffar Aneja, Kuldip Singh Sood, Savita Bansal, Naresh Kumar Sharma.
1. Assistant Professor, Department of Anatomy, SGT Medical College Gurgaon,
2. Assistant Professor, Department of Anatomy ,SGT Medical College Gurgaon,
3. Professor \& Head, Department of Anatomy, SGT Medical College Gurgaon.
4. Assistant Professor, Department of Pathology, Manav rachna University, Faridabad.
5. Assistant Professor, Department of Physiology, SHKM GMC Mewat.

\section{CORRESPONDING AUTHOR:}

Dr. Amit Kumar Saxena, C/O Mr. V.K. Mahindroo,

Nil -37 A, Malviya Nagar, New Delhi.

E-mail: amitsonu33@hotmail.com

BACKGROUND: Dermatoglyphics is the scientific study of epidermal ridges and their configurations on the palmar region of hand and fingers and plantar region of foot and toes. The myocardial infarction is almost always caused by coronary artery disease. Against the genetic background of dermatoglyphic patterns and coronary artery disease, the study was undertaken to determine the correlation between them. AIMS To do a comparative study of the dermatoglyphics (finger tip pattern) in patients with myocardial infarction and control group and to assess the usefulness of finger tip pattern in serving as a predictor for myocardial infarction. SETTING AND DESIGN: The study was done in 200 persons of age between 40 to 75 years . Out of them,100 were confirmed cases of CAD and 100 were normal healthy controls. METHODS AND MATERIAL: The finger and palmar prints of both hands were taken on white paper by Ink method and kores duplicating ink was used for taking the prints. STATISTICAL ANALYSIS USED: In statistical analysis SPSS software was used and $Z$ test was used. The p value less than .001 and .05 was considered statistically significant.

RESULTS AND CONCLUSIONS: It was found that the total number of whorls are significantly higher in patients with myocardial infarction and total number of loops are significantly lower in patients with CAD. Such difference was significant only in right thumb, left thumb, right ring finger and left little finger. Similarly, loops were significantly less in right thumb, right index finger, right and left little finger. With regard to high incidence of MI, it can be concluded that the knowledge of dermatoglyphics in patients with MI can be utilized to find out genetic correlation. The existence of such relation might be important in the screening program for prevention of MI.

KEYWORDS: Dermatoglyphics patterns, myocardial infarction, coronary artery disease, loops, whorls, arches.

INTRODUCTION: Dermatoglyphics is the scientific study of epidermal ridges and their configurations on the palmar region of hand and fingers and plantar region of foot and toes ${ }^{1}$. The term dermatoglyphics was coined by Cummins ${ }^{1}$ and Midlo in 1926 and was derived from Greek words ' derma' means skin and 'glyphics' means carvings². All studies of dermal ridge arrangement including genetic, anthropology and Egyptology are classified under dermatoglyphics. The 
dermatoglyphic patterns make their appearance as early as $12^{\text {th }}$ to $13^{\text {th }}$ week of gestation. Dermatoglyphics patterns have following features:

* They are unique

* They are permanent and once formed these patterns do not change throughout life except in the dimension in the proportion to the growth of an individual ${ }^{2}$.

* They are universal

* They are inimitable

They are classifiable. Generally finger prints are of three types that is whorl, loop, arch.

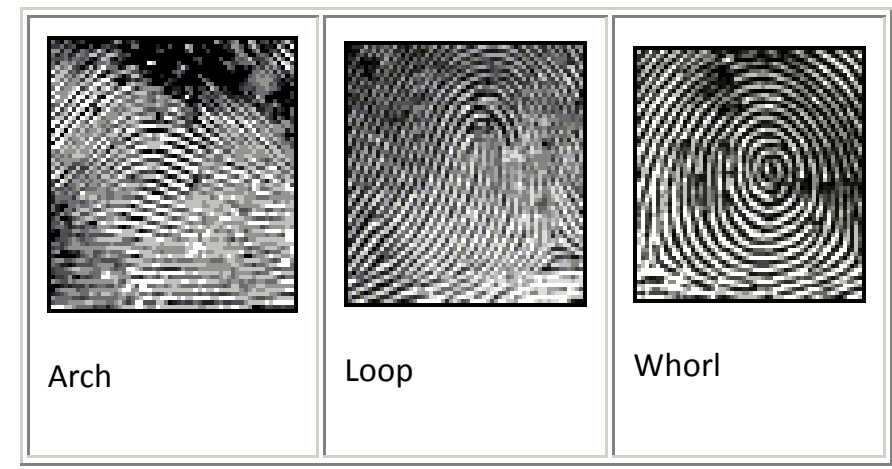

Development of dermatoglyphic pattern is under genetic control this is evident from the clear resemblance of dermatoglyphics among related person. Dermatoglyphics as a diagnostic aid is now well established in a number of diseases, which have a strong hereditary basis, and is employed as a method of screening abnormal anaomalies ${ }^{3,4}$.

Myocardial Infarction is almost always caused by coronary artery disease (CAD). The most common cause of myocardial ischemia is atherosclerotic disease of an epicardial coronary artery or arteries sufficient to cause a regional reaction in myocardial blood flow and inadequate reperfusion of the myocardium supplied by the involved coronary arteries. Coronary artery is the leading cause of mortality and morbidity worldwide, with $>4.5$ million deaths occurring in the developing world. Despite a recent decline in developed countries both CAD mortality and the prevalence of CAD risk factors continue to rise in rapidly in developing world. 5 In the United States, diseases of the heart are the leading cause of death, causing a higher mortality than cancer. At least 250000 people die of a heart attack before they reach the hospital. ${ }^{6}$

Ischemic heart disease (IHD) is likely to become the most common cause of death worldwide by $2020.6,7$

The etiology of CAD is multifactorial with genetics playing an important role. The knowledge of dermatoglyphics in patients with CAD can be utilized to find out the genetic correlation. Thus, with regard to high incidence of CAD in the world, the existence of such relation might be important in screening program for prevention of myocardial infarction. Therefore, there is a scope of further research in this field. The present study is a step towards the same.

\section{AIMS:}

- To do a comparative study of the dermatoglyphics (finger tip pattern) in patients with myocardial infarction and control group. 
- To assess the usefulness of finger tip pattern in serving as a predictor for myocardial infarction

MATERIAL AND METHODS: The present study was carried out in the Department Of Anatomy, MGM Medical College Indore Madhya-Pradesh The study was conducted on 200 subjects out of these 100 were confirmed cases of myocardial infarction having coronary artery disease. The total number of controls was 100 and having no clinically proven CAD. The age group selected for cases and controls were between 40-75 years. The confirmed cases of MI were taken from the Division of Intensive Coronary Care Unit of the Department of Medicine, M.Y. Hospital and M.G.M. Medical College, Indore. The controls were taken from attendant of patients. The individuals with history/ family history of hypertension, diabetes, or any cardiac problem, mental illness , congenital abnormality were excluded from control and baseline ECG, serum TGS and serum cholesterol was done for the controls. The patient and control group were explained about the purpose of study and written consent was taken from them.

The ink method as described by Cummins and Midlo was used for the study for taking the fingerprints. ${ }^{8}$

It required ink pad, kores duplicating ink, roller, proforma for taking fingerprints, magnifying lens, soap and cardboard.

The hands were thoroughly washed with soap before taking prints and well dried.

Then requisite amount of ink was placed on ink pad and evenly distributed with the help of roller. Then each finger of both hands was rolled with medial side to laterally on the pad or cardboard and then placed on paper with one lateral edge and then rolled over in opposite direction.

Fingerprints were recorded carefully and analyzed for pattern type.

Percentage of whorl, loop and arches were compared into two groups.

STATISTICS: For each subject 10 fingerprints were taken. Overall 1000 fingerprints for cases and 1000 fingerprints for control group was obtained for analysis.

In statistical analysis SPSS software was used and large sample test Z test was used.

For the comparison of percentage of different finger prints taken $\mathrm{Z}$ test was used for difference of proportion. For calculation of mean age $\mathrm{Z}$ test for difference of means was calculated.

RESULTS: In this study 200 persons were selected according to criteria given in the material and methods. Out of 200 persons, 100 cases who were known cases of CAD were treated as Study Group and 100 were Healthy Controls.

The total number of fingerprints pattern recorded was 2000, out of these 1000 were for cases and 1000 were for controls.

The age group selected for both cases and controls was between 40 to 75 years.

Out of 100 cases, 84 were males and 16 were females.

The mean age of cases and controls for male and female is as follows:

Total male cases

Mean age

Total number of females cases

Mean age
: 84

: $52.33 \pm 9.08$.

: 16

: $\quad 59.25 \pm 7.16$ 
Mean age of total no. of cases

Total number of controls was

Total number of male controls

Mean age of male

Total number of female controls

Mean age of female controls

Mean age of total no. of controls
: $\quad 53.44 \pm 9.10$

: 100

74 were males and 26 were females

: 74

: $\quad 57.70 \pm 7.95$

: 26

: $\quad 50.32 \pm 8.33$

: $\quad 51.57 \pm 7.99$.

Fingerprints patterns of both cases and controls were analyzed by using $\mathrm{Z}$ test. The percentage of total number of different types of finger prints, comparison of fingerprint patterns between case and control in individual digit and comparison of different types of fingertip patterns in control and MI patients.

Table No. 1 shows comparison of total number of different types of fingerprints in cases (MI patients) and controls.

It is observed that total numbers of whorls in patients with myocardial infarction were $39.6 \%$ and total number of whorls in control is 25.4 . The $P$ value $<0.001$, it means that total number of whorls was significantly higher in patients with myocardial infarction as compared to control group.

While there was less number of loops $(51.8 \%)$ in patients with myocardial infarction as compared to control group (68.0\%). The P value $<0.001$, means that total number of loops is significantly lower in the patients with myocardial infarction.

Table No. 1: Comparison of the total number of finger prints between patients and control group

\begin{tabular}{|l|l|l|l|l|}
\hline Type of finger prints & Cases (\%) & Controls (\%) & P value & Significance \\
\hline Whorls & 39.6 & 25.4 & $<0.001$ & Significant \\
\hline Loops & 51.8 & 68.0 & $<0.001$ & Significant \\
\hline Arches & 8.6 & 6.6 & $>0.001$ & Not significant \\
\hline
\end{tabular}

Since there was significant difference in total number of loops and whorls in the two groups, they were further compared in individual digit. 


\section{ORGINAL ARTICLE}

Table No. 2(a) and 2(b) shows comparison of percentage of whorls in individual digit in two groups.

Table No. 2(a) Comparison of Percentage of Whorls in Each Digit in Two Groups of Right Hand

\begin{tabular}{|c|c|c|c|c|c|}
\hline \multirow[t]{2}{*}{ Group } & \multicolumn{5}{|l|}{ Right hand } \\
\hline & Thumb & Index finger & $\begin{array}{l}\text { Middle } \\
\text { finger }\end{array}$ & Ring finger & Little finger \\
\hline \multicolumn{6}{|l|}{ Whorls } \\
\hline Cases & 48 & 42 & 28 & 64 & 42 \\
\hline Controls & 22 & 26 & 26 & 38 & 20 \\
\hline $\mathrm{P}$ value & $<0.001$ & $>0.001$ & $>0.001$ & $<0.001$ & $<0.001$ \\
\hline Significance & Significant & $\begin{array}{l}\text { Not } \\
\text { significant }\end{array}$ & $\begin{array}{l}\text { Not } \\
\text { significant }\end{array}$ & Significant & Significant \\
\hline
\end{tabular}

Table No. 2(b) Comparison of Percentage of Whorls in Each Digit in Two Groups of Left Hand

\begin{tabular}{|l|c|c|c|c|c|}
\hline \multirow{2}{*}{ Group } & \multicolumn{5}{c|}{ Left Hand } \\
\cline { 2 - 6 } & Thumb & Index finger & Middle finger & Ring finger & Little finger \\
\hline Whorls & 38 & 32 & 22 & 50 & 38 \\
\hline Cases & 20 & 34 & 18 & 32 & 18 \\
\hline Controls & $<0.001$ & $>0.001$ & $>0.001$ & $>0.001$ & $<0.001$ \\
\hline P value & Significant & Not significant & Not significant & Not significant & Significant \\
\hline Significance &
\end{tabular}

WHORLS: All the digits in patients shows higher percentage of whorls. For the right hand, the difference being significant statistically in right thumb, right ring finger and right little finger, there value in cases were $48 \%, 64 \%$ and $42 \%$ respectively for cases and $22 \%, 38 \%$ and $20 \%$ respectively for the control group, which is statistically highly significant $(\mathrm{P}<0.001)$.

For the left hand, the difference being significant in left thumb and little finger, there values for cases were $38 \%$ and $38 \%$ respectively and for control group, they were $20 \%$ and $18 \%$ respectively. It was statistically highly significant $(\mathrm{P}<0.001)$.

$\mathrm{P}$ value is $<0.001$ which shows that whorls were significantly higher in patients of myocardial infarction as compared to controls.

Table No. 3(a) and 3(b) shows comparison of percentage of loops in individual digit in two groups. 


\section{ORGINAL ARTICLE}

Table No. 3(a) Comparison of Percentage of Loops in Each Digit in Two Groups of Right Hand

\begin{tabular}{|l|l|l|l|l|l|}
\hline \multirow{2}{*}{ Group } & Right hand & \multicolumn{5}{l|}{} \\
\cline { 2 - 6 } & Thumb & Index finger & Middle finger & Ring finger & Little finger \\
\hline Loops & 42 & 40 & 72 & 34 & 48 \\
\hline Cases & 78 & 62 & 72 & 46 & 72 \\
\hline Controls & $<0.001$ & $<0.001$ & $>0.001$ & $>0.001$ & $<0.001$ \\
\hline P value & Significant & Significant & $\begin{array}{l}\text { Not } \\
\text { significant }\end{array}$ & $\begin{array}{l}\text { Not } \\
\text { significant }\end{array}$ & Significant \\
\hline Significance & &
\end{tabular}

Table No. 3(b) Comparison of Percentage of Loops in Each Digit in Two Groups of Left Hand

\begin{tabular}{|l|l|l|l|l|l|l|}
\hline \multirow{2}{*}{ Group } & \multicolumn{2}{l}{ Left Hand } & \multicolumn{2}{l|}{} \\
\cline { 2 - 6 } & Thumb & Index finger & Middle finger & Ring finger & Little finger \\
\hline Loops & 60 & 56 & 68 & 54 & 44 \\
\hline Cases & 72 & 54 & 78 & 62 & 84 \\
\hline Controls & $>0.001$ & $>0.001$ & $>0.001$ & $>0.001$ & $<0.001$ \\
\hline P value & $\begin{array}{l}\text { Not } \\
\text { significant }\end{array}$ & $\begin{array}{l}\text { Not } \\
\text { significant }\end{array}$ & $\begin{array}{l}\text { Not } \\
\text { significant }\end{array}$ & $\begin{array}{l}\text { Not } \\
\text { significant }\end{array}$ & Significant \\
\hline Significance & &
\end{tabular}

LOOPS: The percentage of loops were significantly lower in right thumb, right index finger and right little finger, they were for the cases were $42 \%, 40 \%$ and $48 \%$ respectively and for control group, they were $78 \%, 62 \%$ and $72 \%$ respectively. It was statistically highly significant $(\mathrm{P}<0.001)$.

For the left hand, loops were significantly lower in the left little finger, their values for the cases were $44 \%$ and for control group it was $84 \%$ respectively. It was statistically highly significant $(\mathrm{P}<0.001)$.

$\mathrm{P}$ value is $<0.001$ which shows that loops were significantly lower in patients of myocardial infarction as compared to controls.

Table No. 4 shows comparison of different types of finger tips in controls and CAD patients.

Table No. 4 Percentage of Persons Showing Different Finger Tip Patterns

\begin{tabular}{|l|l|l|l|l|}
\hline Finger tip pattern & $\begin{array}{l}\text { Cases (\%) } \\
(\mathbf{n = 1 0 0 )}\end{array}$ & $\begin{array}{l}\text { Controls } \\
(\mathbf{\%}) \\
(\mathbf{n = 1 0 0 )}\end{array}$ & P value & Significance \\
\hline Whorls & 90 & 60 & $<0.001$ & Significant \\
\hline Loops & 94 & 98 & $>0.05$ & Not significant \\
\hline Arches & 22 & 20 & $>0.05$ & Not significant \\
\hline
\end{tabular}

It shows that significantly more number of CAD patients shows presence of whorl in one or more finger as compared to control. It was $90 \%$ in cases and $60 \%$ in control ( $\mathrm{p}$ value $<0.001$ ). 
The difference in incidence of loops and arches was not statistically significant.

DISCUSSION AND CONCLUSIONS: The present study recorded the finger print pattern of all 10 fingers of 200 persons of age group 40-75 years.

It was found that the total number of whorls is significantly higher in patients with MI and total number of loops are significantly lower in patients with CAD.

The observations of the present study are supported by observation found in earlier studies. Rashad \& Mi $^{9}$ in 1975 also reported significantly higher frequency of whorl in myocardial infarction patients . In 1978, Rashad et al10 also reported significantly higher frequency of whorls and less number of loops in his patients and they also found higher absolute ridge count in patients with myocardial infarction.

In 1981 Anderson et al11 also noted decrease in loop pattern and increase in whorl pattern in myocardial infarction but not statistically significant difference when compared with controls as in our study it is statistically significant.

Rao12 in 1995 reported that person who have predominant whorls in fingerprints have higher incidence of widespread arterial and venous thrombosis.

Bhatt13 in 1996 presented data showing significant higher incidence of whorl and lower incidence of loops in patients with MI.

In 1994 Kaseem \& Mokhtar14 reported significant association in finger tip pattern, ridge count, and palm pattern in patient with CAD and control group.

In 1998 Mishra et al 15 reported the significant increase in whorls in patient with coronary heart disease.

In 2000, Dhall et al16 reported increased incidence of whorl and less number of loops in patients with MS as compared to control group. In 2002, Jalali \& Hajian- Tilaki17 reported that significant decrease in loops and increase number of arch type of finger tip pattern in patient with $\mathrm{MI}(\mathrm{P}<.000) 1$ while in the presents study not statistically significant difference in arches when compared with controls ( $\mathrm{P}>$.001).

In 2012 Chimne \& Ksheersagar18 reported significant decreased loops and increased whorls in CAD patients $(\mathrm{P}<.001)$.

So observations of present study add support to these earlier observations. It is apparent that there do exists a relation between dermatoglphyic patterns and CAD .

The conclusion derived from present study is that CAD is most important cause of mortality and morbidity in the world. CAD causes more death and disability and incurs greater economic cost than any other illness in developing world. With the urbanization in the developing world, the prevalence of risk factor for CAD is increasing in these regions, especially India. With regard to high incidence of MI, the knowledge of dermatoglyphics in patients with MI can be utilized to find out genetic correlation.

The existence of such relation might be important in the screening programme for prevention of MI. If an individual with special patterns of dermatoglyphics is susceptible to MI, he/she can be screened for prevention by controlling other risk factors in early detection programme.

So, with the help of fingerprint pattern it might be helpful for screening of persons for CAD in rural areas where there are lack of diagnostic facilities. 
ACKNOWLEDGEMENT: It is with a deep sense of gratitude and reverence that I express my sincere thanks to my guide Dr. Mrs. Sudha Shrivastava, Professor and Head, Department of Anatomy, and Dr. Anil Bharani, Professor, Department of Medicine, for allowing me to undertake this study in the institution and I am also thankful to Pawan goyal (Statistician) \& K.K. Dwivedi, Finger Print Expert, Crime Branch, S.P. Office, Indore, who helped me in analysing the finger tip patterns taken in the study.

\section{REFERENCES:}

1. Harold Cummins and Charles Midloo. Palmar and plantar epidermal configurations (Dermatoglyphics) in European Americans. Am J Phys Anthropol 1926; 9 :471-502.

2. Penros LS. Finger prints,palms and chromosomes. Nature 1963; 197: 933-938.

3. Sir Francis Galton. Fingerprints. London: MacMillan \& Co. New York 1892; 5 : 77-81.

4. Schaumann B , Alter M. Dermatoglyphics in Medical Disorders. Springer-Verlag New YorK 1976, 187-189.

5. Okrainec K, Banerjee DK, Eiseberg MJ. Coronary Artery Disease in developing world. Amer.Heart J.;2004;148:7-15.

6. Andrew PS,Braunwald E. Harrison's Textbook of Internal Medicine. 16thed. United States of America : Mc Graw Hill Publication; 2005.

7. Kumar V,Abbas AK,Fausto N, Robbins and Cotran Pathologic Basis Of Disease.2007, 7THed, Saunders Elsevier Publication, Philadelphia, Indian Reprint, pp:571-87.

8. Cummins H, Midloo C, Finger Prints, Palms and Soles. An Introduction To Dermatoglyphics. New York ;Dovar pub.INC;1961.

9. Rashad MN, Mi MP. Dermatoglyphics traits in patients with cardiovascular disorders. Amer J Physl Anthropol 1975;42(2):281-83.

10. Rashad MN, Mi MP, Rhoads G. Dermatoglyphic studies of myocardial infarction patients Hum Hered 1978; 28:16.

11. Anderson MW, Haug PJ, Critchfield G. Dermatoglyphic features of myocardial infarction patients. Amer J Physl Anthropol 1981; 55(4):523-27.

12. Rao UR. Anticardiolipin antibodies. Medicine Update APICON 1995;17-19.

13. Bhatt SH. New signs of myocardial infarction. Medicine Update 1996; Sept : 411-416

14. Kaseem NS, Mokhtar MM, Elbel- Bessy MF. Genetic markers in coronary heart diseas. J Egypt Public health Asso. 1994; (5-6):359-78.

15. Misra S, Dhiman SR , Kaur K . Finger Dermatoglyphics and Coronary Heart Disease. Man in India 1998; 78(1-2): 127-33.

16. Dhall U, Rathee S,Dhall A. Utility of finger prints in myocardial infarction patients. J Anat Soc India 2000; 49(2):153-54.

17. Jalili F, Hajian-Tilaki KO. A comparative study of dermatoglyphic pattern in patients with myocardial infarction and control group. Acta Medica Iranica 2002; 40(3):187-91.

18. Chimne DH,Ksheersagar DD. Dermatoglyphic patterns in angiographically proven coronary artery disease. J Anat Soc India 2012; 61(2) :262-68. 